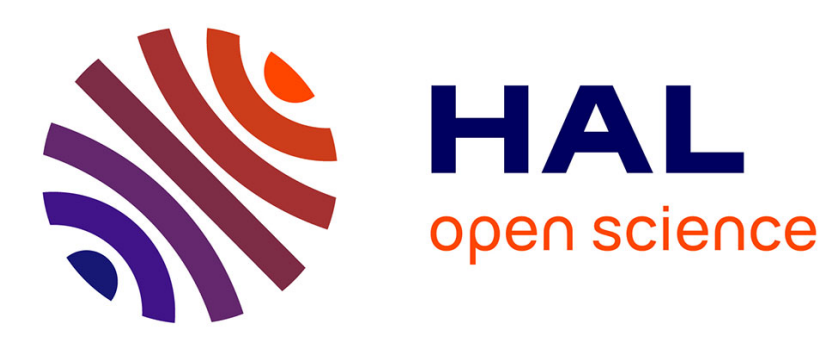

\title{
An Interactive Tool for the Optimization of Freeze-Drying Cycles Based on Quality Criteria
}

Ioan-Cristian Trelea, Stéphanie Passot, Fernanda Fonseca, Michele Marin

\section{To cite this version:}

Ioan-Cristian Trelea, Stéphanie Passot, Fernanda Fonseca, Michele Marin. An Interactive Tool for the Optimization of Freeze-Drying Cycles Based on Quality Criteria. Drying Technology, 2007, 25 (5), pp.741-751. 10.1080/07373930701370100 . hal-01537101

\section{HAL Id: hal-01537101 \\ https://hal-agroparistech.archives-ouvertes.fr/hal-01537101}

Submitted on 14 Jun 2017

HAL is a multi-disciplinary open access archive for the deposit and dissemination of scientific research documents, whether they are published or not. The documents may come from teaching and research institutions in France or abroad, or from public or private research centers.
L'archive ouverte pluridisciplinaire HAL, est destinée au dépôt et à la diffusion de documents scientifiques de niveau recherche, publiés ou non, émanant des établissements d'enseignement et de recherche français ou étrangers, des laboratoires publics ou privés. 


\title{
AN INTERACTIVE TOOL FOR THE OPTIMISATION OF FREEZE- DRYING CYCLES BASED ON QUALITY CRITERIA
}

\author{
Ioan Cristian Trelea, Stéphanie Passot, Fernanda Fonseca and Michèle Marin \\ UMR Génie et Microbiologie des Procédés Alimentaires, INRA, INA P-G, \\ BP 01, 78850 Thiverval-Grignon, France, E-mail : trelea@grignon.inra.fr
}

\begin{abstract}
Among existing dehydration methods, freeze-drying has unique benefits for the stabilisation and preservation of biological activity of pharmaceutical products, but remains an expensive and time-consuming process. A userfriendly software tool was developed, allowing for interactive selection of process operating condition profiles in order to maximise process productivity while insuring product quality preservation. The software is based on a dynamic, one-dimensional heat and mass transfer model, which can accurately represent both the primary and secondary drying stages and the gradual transition between them. The model was validated in a wide range of operating conditions: -25 to $+25^{\circ} \mathrm{C}$ shelf temperature and 10 to $34 \mathrm{~Pa}$ total pressure. By comparing a reference sucrose solution with a formulated pharmaceutical product containing polyvinylpyrrolidone (PVP), it is shown that controlling product properties such as glass transition temperature and sorption isotherm can reduce the minimum achievable cycle duration by 12 h (33\%).
\end{abstract}

Keywords: lyophilization, dynamic modeling, optimization, glass transition temperature.

\section{INTRODUCTION}

In pharmaceutical industry, freeze-drying is widely used to preserve proteins and polypeptides, which are physically and/or chemically unstable in aqueous solutions (1). The improved stability of freeze-dried proteins provides many benefits such as storage stability at ambient temperature, extended shelf life, convenient handling 
and transport. However, freeze-drying is known to be a time-consuming and expensive process. An over conservative freeze-drying cycle results in long process time, added production costs, unnecessary consumption of drying capacity, and may compromise protein stability. Various process variables affect the efficiency of the freeze-drying process. The product temperature is a determinant factor for both productivity and product quality (2-4). The sublimation is generally faster at higher temperatures, but drying at excessive temperatures results in a loss of the pore structure obtained by freezing, which is defined as the collapse phenomenon by Pikal and Shah (5) and therefore in rejection of the batch. For amorphous formulations, the collapse is usually associated with the glass transition temperature of the maximally freeze-concentrated phase. The product temperature results from the shelf temperature and the chamber pressure applied and is not directly controlled during freeze-drying process. In practice, the appropriate shelf temperature and chamber pressure conditions are frequently established empirically in a "trial-and-error" experimental approach and many manufacturing processes are far from optimal (6). Theoretical modelling can provide a better understanding of the impact of process and formulation variation on cycle time and product temperature history and, thereby, facilitate process development and on-line monitoring (7).

This study presents a software tool for interactive selection of the process operating conditions: shelf temperature profile, chamber pressure profile, condenser temperature, etc. While changing the operating conditions, the user monitors process parameters relevant for product quality and productivity: product temperature and glass transition temperature at critical points in order to asses product stability, as well as the residual moisture content which determines the cycle duration. Unlike fully automated optimisation $(8,9)$, the user retains complete control over the selected operating conditions, which can be advantageous for gaining insight into the limiting factors and for taking into account semi-empirical, experience-based considerations, difficult to encode in a formal optimisation process. The software is based on a simple yet accurate one-dimensional dynamic model of heat and mass transfer with associated product quality indicators. The development of this model was motivated by the necessity of very quick simulation compared to many existing complex multi-dimensional models (1013). Short simulation time, less than $0.2 \mathrm{~s}$ on a standard PC (AMD Athlon ${ }^{\circledR}$ processor at $2 \mathrm{GHz}$ ), allows comfortable interaction with the user. Detailed output information is also available for posterior analysis under Matlab $^{\circledR}$ and Excel ${ }^{\circledR}$, such as temperature, vapour pressure, residual moisture profiles in relevant locations in the product layer and in the chamber. 


\section{MATERIALS AND METHODS}

\section{Experimental}

\section{Product formulations}

Two product formulations were considered in this study. The first formulation (coded S) was a 5\% sucrose and $10 \mathrm{mM}$ Tris-HCl solution taken as reference. The second formulation (coded PS) contained 4\% polyvinylpyrrolidone (PVP), 1\% sucrose and $10 \mathrm{mM}$ of Tris- $\mathrm{HCl}$ and was selected for its efficient protein stabilisation properties (14). Sucrose was purchased from Prolabo (Paris, France) and polyvinylpyrrolidone (with a reported average molecular weight of 25,000 Da) from Merck (Darmstadt, Germany).

\section{Freeze-drying protocols}

One millilitre of each formulation was placed in $4 \mathrm{~mL}$ glass vials. The vials (a total of 213 vials per cycle) were placed on an aluminium tray and loaded onto the shelf of a SMH 15 freeze-drier (Usifroid, Maurepas, France). The cycle consisted of freezing at $-45^{\circ} \mathrm{C}$ (shelf cooling rate at $0.6^{\circ} \mathrm{C} / \mathrm{min}$ and holding at $-45^{\circ} \mathrm{C}$ for $2 \mathrm{~h}$ ), followed by primary drying under various conditions of shelf temperature $\left(-5^{\circ} \mathrm{C},-15^{\circ} \mathrm{C},-5^{\circ} \mathrm{C}, 5^{\circ} \mathrm{C}, 15^{\circ} \mathrm{C}\right.$ and $\left.25^{\circ} \mathrm{C}\right)$ and chamber pressure $(10 \mathrm{~Pa}, 18 \mathrm{~Pa}, 26 \mathrm{~Pa}$ and $34 \mathrm{~Pa})$ and, finally, a secondary drying of 6 hours at $25^{\circ} \mathrm{C}$ and $10 \mathrm{~Pa}$. Depending on the experiment, the heating rates of the shelf temperature were of $0.1^{\circ} \mathrm{C} / \mathrm{min}, 0.25^{\circ} \mathrm{C} / \mathrm{min}$ or $1^{\circ} \mathrm{C} / \mathrm{min}$.

Product temperature was measured by two thermocouples placed at the bottom of two different vials. A moisture sensor (Panametrics Ltd, Shannon, Ireland) was used to monitor the partial vapour pressure in the chamber.

Lyophilized samples were equilibrated at $25^{\circ} \mathrm{C}$ under the following saturated salt solutions of constant water activities ( $\mathrm{a}_{\mathrm{w}}$ values are shown in parenthesis): $\mathrm{CH}_{3} \mathrm{COOK}(0.23), \mathrm{MgCl}_{2} \cdot 6 \mathrm{H}_{2} \mathrm{O}$ (0.33), $\mathrm{K}_{2} \mathrm{CO}_{3}(0.44)$, $\mathrm{Mg}\left(\mathrm{NO}_{3}\right)_{2} \cdot 6 \mathrm{H}_{2} \mathrm{O}$ (0.53), $\mathrm{NaCl}(0.75)$ and $\mathrm{KCl}(0.84)$.

\section{Differential scanning calorimetry}

DSC was used to determine the glass transition temperature of liquid samples before freeze drying, and samples that were freeze dried and equilibrated to different relative humidities. DSC measurements were performed using a power compensation differential scanning calorimeter (DSC) (Pyris 1 model; Perkin Elmer LLC, Norwallk, CT, USA), equipped with a liquid nitrogen accessory (CryoFill, Perkin Elmer). Between 5 and 20 mg of each 
sample were placed in $50 \mu \mathrm{L}$ Perkin-Elmer DSC aluminium sealed pans, and a empty pan was used as a reference. Cooling and heating rates of $10^{\circ} \mathrm{C} / \mathrm{min}$ were used. The glass transition temperatures were reported as the midpoint temperature of the heat capacity step associated with the glass transition, in accordance with the ASTM Standard Method E 1356-91.

Liquid samples were cooled to $-120^{\circ} \mathrm{C}$ to ensure temperature stability and sample equilibration, and scanned for the first time to $25^{\circ} \mathrm{C}$. This conventional thermal cycle was replicated once to verify the absence of time dependent changes in thermal behaviour. Dried samples were cooled to $-40^{\circ} \mathrm{C}$ and then heated to $200^{\circ} \mathrm{C}$.

\section{Water content determination}

Water content of the freeze-dried product and the samples equilibrated under different relative humidity conditions was measured by the Karl Fisher titration method using a Metrohom KF 756 apparatus. At least $20 \mathrm{mg}$ of powder were mixed with $2 \mathrm{~mL}$ of dry methanol and titrated with Riedel-deHaen reagent (Seelze, Germany).

\section{Water activity measurement}

Water activity of samples from sorption isotherms at $25^{\circ} \mathrm{C}$ was measured by an aw meter FA-st/1 (GBX Scientific Instruments, Romans sur Isère, France). Measurements were made with dynamic method and each result was the average value of 10 measurements once the stability had been reached.

\section{Dynamic model of the freeze-drying process}

\section{Assumptions}

A conventional one-dimensional freeze-drying model of heat and mass transfer was developed, based on the following assumptions:

A1. The product and the dryer state is described by relevant state variables in six key points shown in Figure 1: shelf, product bottom, sublimation front, product top, freeze-drying chamber and condenser. The heat and mass transfers are assumed to take place between these points.

A2. Slow dynamics such as sublimation front movement and residual water desorption are described explicitly by differential equations. Relatively fast dynamics (compared to the typical duration of a freeze-drying cycle) such as heat transfer in the frozen and in the dry product layers, as well as the mass transfer in gaseous phase, are assumed to be in quasi-steady state and are described by algebraic equations. This assumption is supported by detailed calculation of the relevant time constants, reported in Appendix 1.

A3. The residual water desorption flux was neglected in the heat and mass balances. A complete model, including the desorption heat and desorption vapour fluxes was also build and tested, and it was found that the contribution of the desorption was actually negligible, confirming earlier findings (15). 
A4. Ice gradually disappears in various product regions. The relative importance of the primary and secondary drying mechanisms is given by the ratio of the remaining sublimation area to the total product cross area.

\section{Control variables}

The shelf, chamber and condenser temperatures, as well as the total chamber pressure are assumed to be imposed by the freeze-drying protocol and known at any moment. They are allowed to vary in time, however.

\section{State variables}

The product state at any given moment is described by the sublimation front position, the temperature and the residual water concentration at the product bottom, front and top.

During the primary drying stage, the front temperature is determined from the heat balance condition at the sublimation front, taking into account assumptions A2 and A3:

$$
\begin{aligned}
& H^{\text {Shelf Front }}\left(Z^{\text {Front }}, P_{t}^{\text {Chamb }}\right) \cdot\left(\Theta^{\text {Shelf }}-\Theta^{\text {Front }}\right)+H^{\text {Front Chamb }}\left(Z^{\text {Front }}, P_{w}^{\text {Sat }}\left(\Theta^{\text {Front }}\right)\right) \cdot\left(\Theta^{\text {Chamb }}-\Theta^{\text {Front. }}\right) \\
& =L_{\text {subl }} K^{\text {Front Cond }}\left(Z^{\text {Front }}\right) \cdot\left(P_{w}^{\text {Sat }}\left(\Theta^{\text {Front }}\right)-P_{w}^{\text {Sat }}\left(\Theta^{\text {Cond }}\right)\right)
\end{aligned}
$$

Eq. (1) expresses the fact that, in the assumed quasi-steady state situation, the net heat flux towards the sublimation front (from the product shelf and from the chamber) mainly serves for ice sublimation. In this equation, the heat transfer coefficients $H^{\text {Shelf Front }}$ and $H^{\text {Front Chamb }}$, as well as the mass transfer coefficient $K^{\text {FrontCond }}$ are calculated using resistance in series formulae (Figure 1). The heat transfer between the shelf and the product bottom includes contact, radiation and gas conduction terms. The heat transfer resistance through the glass vial bottom turned out to be negligible. The gas conduction term depends on the total pressure in the freeze-drying chamber (2). The heat transfer between the product bottom and the sublimation front takes place by conduction through the frozen layer, and hence depends on its thickness (front position). The heat transfer between the sublimation front and the chamber takes into account transfer through the dry layer to the product top (by gas conduction, vial walls and radiation) and from the product top to the chamber, mainly by radiation. The mass transfer resistance includes flow resistance through the porous dry layer (depending on its thickness), from product top to the freeze-drying chamber (specifically to the location of the partial vapour pressure sensor) and from the chamber to the condenser. These last two transfer coefficients depend on the freeze-dryer design. For sake of readability and completeness, detailed expressions for all heat and mass transfer coefficients are given in Appendix 2 in a tabular form.

Eq. 1 encodes the unavoidable interdependence between the heat and mass fluxes. The heat flux depends on the sublimation front temperature and determines the mass flux. The mass flux creates a vapour pressure increase in the dry layer, which in turn determines the sublimation front temperature, because of the local (at the sublimation 
front) equilibrium condition between ice and vapour. In practice, solving Eq. 1 gives the sublimation front temperature.

The front position is determined from the sublimation mass flux by considering the volume liberated by the sublimated ice:

$$
\frac{d Z^{\text {Front }}}{d t}=\frac{H^{\text {FrontCond }}}{D^{I c e} A}\left(P_{w}^{\text {Sat }}\left(\Theta^{\text {Cond }}\right)-P_{w}^{\text {Sat }}\left(\Theta^{\text {Front }}\right)\right)
$$

During the secondary drying stage, the front position is fixed to zero and the front temperature is formally taken equal to the product bottom temperature.

During both drying stages the residual water concentration at the top of the dry layer is calculated using a firstorder desorption kinetic:

$$
\frac{d C^{\text {Top }}}{d t}=\frac{1}{\tau_{\text {Des }}}\left[C_{E q u}\left(\frac{P_{w}^{\text {Top }}}{P_{w}^{\text {Sat }}\left(\Theta^{\text {Top }}\right)}\right)-C^{\text {Top }}\right]
$$

The equilibrium water content $C_{E q u}$ is given by the sorption isotherm, as described in the following section. It depends on the ratio between the actual vapour pressure and the saturation pressure. At equilibrium, the ratio of these pressures would represent the water activity of the product. The actual vapour pressure is determined from the mass flux and the resistance in series model (Figure 1).

Similar equations were written for the product top and for the sublimation front. During the primary drying, at the product bottom and at the sublimation front, the vapour is in equilibrium with the ice according to assumption A2 and the pressure ratio is equal to one. During the secondary drying stage, the front position is formally identical to the product bottom and the partial vapour pressure is in equilibrium with the chamber and the condenser. This later condition results from assumptions A2 and A3: the desorption mass flux being negligible, there is no local pressure increase in the dry layer (16).

Finally, the model consists of a system of four differential equations (for the front position and the residual moisture contents at the product bottom, front and top) and one algebraic equation for the front temperature. The five coupled equations are solved simultaneously using the Matlab ${ }^{\circledR}$ numeric computation software (Natick, MA, USA). A detailed description of the model is given in the Appendix 2.

\section{Output variables}

The model allows a relatively straightforward calculation of various quantities of practical interest, in any relevant location among those shown in Figure 1, such as: product temperatures, glass transition temperatures 
important for the product stability during drying, partial vapour and neutral gas pressures, average residual moisture content important for assessing the end of the drying cycle, evolution of the product mass in a vial, etc.

\section{Gradual transition between the primary and the secondary drying stages}

In practice, the freeze-drying conditions are not perfectly homogeneous (17). Lack of homogeneity appears both among vials, e.g. due to position on the shelf, wall chamber radiation, unequal vial filling etc. as well as inside each vial, e.g. due to heat conduction through vial walls, lack of planarity of the vial bottom, etc. At the scale of the freeze-dryer, the transition between the primary (I) and the secondary (II) drying stages appears gradual. According to assumption A4, this gradual "transition function" was defined as the ratio of the remaining sublimation area to the total product cross area:

$$
\frac{A_{(I)}(t)}{A^{\text {Tot }}}=f\left(Z^{\text {Front }}(t)\right)
$$

During the transition between stages, both models for the primary and the secondary drying are run in parallel, each with its own product cross section area:

$$
A_{(I)}=f\left(Z^{\text {Front }}\right) A^{\text {Tot }} \quad A_{(I I)}=\left(1-f\left(Z^{\text {Front }}\right)\right) A^{\text {Tot }}
$$

The reported global values of the relevant variables are averages, weighted according to the transition function:

$$
\begin{aligned}
& \Theta^{\text {Front }}=f\left(Z^{\text {Front }}\right) \Theta_{(I)}^{\text {Front }}+\left(1-f\left(Z^{\text {Front }}\right)\right) \cdot \Theta_{(I I)}^{\text {Front }} \\
& \frac{d Z^{\text {Front }}}{d t}=f\left(Z^{\text {Front }}\right) \frac{d Z_{(I)}^{\text {Front }}}{d t}+\left(1-f\left(Z^{\text {Front }}\right)\right) \cdot 0 \\
& \frac{d C^{\text {Top }}}{d t}=f\left(Z^{\text {Front }}\right) \frac{d C_{(I)}^{\text {Top }}}{d t}+\left(1-f\left(Z^{\text {Front }}\right)\right) \frac{d C_{(I I)}^{\text {Top }}}{d t}
\end{aligned}
$$

Similar weightings are used for the other state and output variables.

The transition function was defined empirically as:

$$
f\left(Z^{\text {Front }}\right)=\left\{\begin{array}{cl}
1 & \text { if } Z^{\text {Front }} \geq Z^{\text {Trans }} \\
\sin \left(\frac{\pi}{2} \frac{Z^{\text {Front }}}{Z^{\text {Trans }}}\right) & \text { if } Z^{\text {Front }}<Z^{\text {Trans }}
\end{array}\right.
$$

Eq. 9 says that the primary drying is the only phenomenon as long as the sublimation front position $Z^{\text {Front }}$ is above some critical transition value $Z^{\text {Trans }}$. Below this value, the relative importance of secondary drying increases until the sublimation front reaches the vial bottom $\left(Z^{\text {Front }}=0\right.$ ), when it becomes the only phenomenon. The value of $Z^{\text {Trans }}$ is a measure of the smoothness of the transition. The larger $Z^{\text {Trans }}$, the longer the transition between the primary and the secondary drying. 


\section{Models of the product properties relevant for cycle optimisation}

\section{Glass transition temperature}

An important condition for product stability in the frozen layer during freeze-drying is absence of collapse (5). The product temperature must remain below the collapse temperature in any point during the whole freezedrying cycle. The collapse temperature is usually about $2^{\circ} \mathrm{C}$ higher than the glass transition temperature of the

freeze-concentrated phase $\Theta_{\text {Glass }}^{\text {Frozen }}$ for formulations that remains amorphous during freezing (5). The stability of the product in the dry layer is insured if the product temperature is maintained below the glass transition temperature (18), which strongly depends on the residual moisture content. The condition on the glass transition temperature was thus retained as the main product stability criterion for both the frozen and the dry layers. The evolution of the glass transition temperature was modelled by the classical Gordon-Taylor equation, slightly modified to take into account the frozen layer:

$$
\Theta_{\text {Glass }}(C)=\max \left\{\Theta_{\text {Glass }}^{\text {Frozen }}, \quad \frac{(1-C) \Theta_{\text {Glass }}^{\text {Dry }}+q_{\text {Gordon }} C \Theta_{\text {Glass }}^{\text {Ice }}}{(1-C)+q_{\text {Gordon }} C}\right\}
$$

where $C$ is the moisture content, $\Theta_{\text {Glass }}^{\text {Dry }}$ and $\Theta_{\text {Glass }}^{I c e}$ are the glass transition temperatures of the perfectly dry product and of the ice respectively and $q_{\text {Gordon }}$ is the Gordon-Taylor shape coefficient. For each product formulation, the Gordon-Taylor coefficient was determined by fitting the considered equation to experimental glass transition data of the samples equilibrated under various relative humidity conditions (Figure 2).

\section{Sorption isotherm}

A quality requirement on the final freeze-dried product is to reach a pre-specified residual moisture content, both under- and over-drying being damageable. Moreover, the glass transition temperature in the dry layer strongly depends on the moisture content. Both these conditions require the modelling of the water desorption process in the dry layer, which in turn requires the knowledge of the sorption isotherm and of the desorption kinetic. None of the commonly used models (Freundlich, Langmuir, BET, GAB) was found to fit experimental sorption isotherm data adequately for the considered formulations. The fit was particularly inappropriate in the region of small water activities (less than 0.2) leading to clearly wrong predictions of the final product moisture content. A piecewise linear model was found to give satisfactory results:

$$
C_{E q u}\left(a_{w}\right)=\min \left\{C_{\text {Max }}, \quad \max \left\{C_{\text {Min }}, \quad q_{\text {Sorp } 1}\left(a_{w}-q_{\text {Sorp } 2}\right)\right\}\right\}
$$


Interactive freeze-drying optimisation

Here $C_{E q u}$ is the equilibrium moisture content, $a_{w}$ the water activity, and the other parameters are constants depending on the product formulation. The maximum adsorbed moisture content $C_{\operatorname{Max}}$ was determined from the glass transition temperature of the frozen product (Figure 2). The fit of this model to the experimental data at $25^{\circ} \mathrm{C}$ is shown in Figure 3.

\section{Desorption kinetic}

The calculation of the residual moisture content evolution in time requires the knowledge of the desorption time constant in addition to the equilibrium moisture content (sorption isotherm). The following exponential desorption kinetic model was used, reflecting a first-order rate desorption mechanism (15):

$$
C(t)=C_{E q u}+\left(C_{I n i}-C_{E q u}\right) e^{-\frac{t}{\tau_{\text {Des }}}}
$$

Here $\tau_{\text {Des }}$ is the desorption time constant. The fit of this model to the experimental data is shown in Figure 4.

\section{RESULTS AND DISCUSSION}

\section{Model validation}

The dynamic freeze-drying model was validated based the on-line measurements of product temperature and partial vapour pressure in the chamber. Additionally, the final average moisture content of the product was checked against the simulated value. The product-specific properties are listed in Table 1 . The characteristics of the freeze-drying apparatus and other product-independent parameters are given in Table 2. The results of the model validation are shown in Figure 5 for the two extreme couples of operating conditions considered in the experimental design: shelf temperature of $-25^{\circ} \mathrm{C}$ with total chamber pressure of $10 \mathrm{~Pa}$, and shelf temperature of $+25^{\circ} \mathrm{C}$ with total chamber pressure of $34 \mathrm{~Pa}$ during primary drying. The agreement between measurements and model predictions is quite satisfactory, taking into account the accuracy of the measurements and the repeatability of the experiments: $\pm 1^{\circ} \mathrm{C}$ for product temperature, \pm 2 Pa for vapour pressure and $\pm 0.01 \mathrm{~kg} / \mathrm{kg}$ for the final moisture content.

\section{Freeze-drying cycle optimisation}

After the validation step, the model was used for freeze-drying cycle optimization by interactive selection of the operating condition profiles and simultaneous monitoring of the critical product quality parameters. In order to 
simplify comparison between the S and PS product formulations, most operating conditions were fixed to their usual values (condenser temperature to $-65^{\circ} \mathrm{C}$, chamber temperature to $+25^{\circ} \mathrm{C}$, total chamber pressure to $10 \mathrm{~Pa}$, final average moisture content target to $0.03 \mathrm{~kg} / \mathrm{kg}$ ) and the only optimized operating condition was the shelf temperature profile.

In all cases, increasing freeze-drying productivity requires increasing the shelf temperature as much as possible, while still satisfying the product stability requirement, i.e. product temperature below the glass transition temperature. Operating the process close to the highest temperature limit is considered beneficial not only for process productivity but also for the distributions of temperature and residual moisture at the end of the drying (19). During the interactive optimisation process, product temperatures are monitored at the bottom of the vial, at the sublimation front and at the top of the product. Glass transition temperatures are computed and displayed for the same points. During primary drying, the limiting factor is usually the bottom temperature. The shelf temperature has to be decreased in time, because the self-cooling effect due to ice sublimation decreases when the mass transfer resistance through the dry layer increases with time. A screenshot of the software tool during the interactive optimisation of the shelf temperature profile is shown in Figure 6.

The top temperature may become limiting, however, if the heat transfer from the chamber is high and the heat conductivity of the dry layer is low, despite the fact that the glass transition temperature at the top increases rapidly when the moisture content of the product decreases. During the secondary drying, the moisture content of the whole product decreases, the glass transition temperature increases everywhere and the shelf temperature can be increased significantly up to a limit imposed by the thermal sensitivity of the biological product.

Variations of the total chamber pressure profile were investigated and were found to have little effect on the product temperature and on the cycle duration. The chamber pressure mainly influences the heat transfer between the shelf and the vial, and similar effect can be easily obtained by manipulating the shelf temperature. Thus maintaining a low pressure and controlling the heat flux by the shelf temperature appears as a good policy $(20,21)$. It should be noted, however, that in the considered pilot-scale freeze-dryer a significant fraction of the transferred heat (up to $50 \%$ at low shelf temperatures) comes from the chamber, mainly by radiation. This need not to be the case in an industrial-scale dryer, when the heat transfer between the shelf and the vials through gas conduction may be dominant ant the pressure effect would be stronger.

The best achievable control policies in terms of cycle duration for the two considered product formulations, $\mathrm{S}$ and PS, are compared in Table 3. As expected, the PS formulation allows higher shelf temperatures because of its higher glass transition temperature, and hence faster heat transfer resulting in a shorter freeze-drying cycle. In 
the considered case, the cycle duration is shorter by 12 hours (33\%) which is significant for process scheduling and designing the freeze-drying capacity on an industrial scale.

\section{CONCLUSION}

A user-friendly software for interactive selection of the operating conditions in a freeze-drying process was written. It was based on a validated dynamic model of the freeze-drying process, allowing very quick and accurate simulations of the primary and secondary drying stages, as well as of the gradual transition between the primary and secondary drying stages. Process productivity and product quality indicators at critical points were monitored simultaneously during the cycle optimisation process. It was shown that the optimal operating policy as well as the achievable cycle duration strongly depend on the physical properties of the product formulation, namely the glass transition temperature, the sorption isotherm and the desorption kinetic.

\section{ACKNOWLEDGEMENT}

E.U. is gratefully acknowledged for its financial support in the framework of the research project LYO-PRO: (GROWTH Project GRD1-2001-40259-RTD). 


\section{APPENDIX 1. TIME CONSTANTS FOR THE HEAT AND MASS TRANSFER}

The considered freeze-drying model assumes quasi steady state heat transfer in the frozen and in the dry product regions, as well as quasi steady state mass transfer in the gas phase of the dry region (Assumption A2). In order to justify these assumptions, the order of magnitude of the involved time constants is estimated below, by considering full dynamic heat and mass balance equations. These equations are based on a lumped parameter approximation (as opposed to a distributed parameter approach, involving partial differential equations), but are sufficient to show that the considered dynamics can be safely neglected compared to the typical duration of a freeze-drying process (100000 s).

\section{Heat transfer dynamics in the frozen product layer}

The dynamic heat balance considers heat accumulation in the frozen layer (resulting in temperature variation) and heat fluxes from the shelf and towards the sublimation front:

$$
\left(M^{\text {Ice }} C^{\text {Ice }}+M^{\text {Dry }} C^{\text {Dry }}\right) \frac{d \Theta^{\text {Frozen }}}{d t}=H^{\text {Shelf Frozen }}\left(\Theta^{\text {Shelf }}-\Theta^{\text {Frozen }}\right)-H^{\text {Frozen Front }}\left(\Theta^{\text {Frozen }}-\Theta^{\text {Front }}\right)
$$

The heat capacity of the frozen layer takes into account the presence of ice and dry matter and depends on the sublimation front position. In the lumped parameter approximation, the equivalent heat transfer coefficient between the shelf and the frozen layer includes heat transfer between the shelf and the product bottom and heat conduction through one half of the frozen layer. Heat transfer between the frozen layer and the sublimation front consists in heat conduction through the other half of the frozen layer. The dynamic heat balance can be written in the following form:

$$
\frac{d \Theta^{\text {Frozen }}}{d t}=\frac{1}{\tau_{\Theta}^{\text {Shelf Frozen }}}\left(\Theta^{\text {Shelf }}-\Theta^{\text {Frozen }}\right)-\frac{1}{\tau_{\Theta}^{\text {Frozen Front }}}\left(\Theta^{\text {Frozen }}-\Theta^{\text {Front }}\right)
$$

Substituting typical numerical values, e.g. $Z^{\text {Front }}=Z^{\text {Tot }} / 2, P_{t}^{\text {Chamb }}=20 \mathrm{~Pa}$ etc., one obtains the time constants $\tau_{\Theta}^{\text {Shelf Frozen }}=564 \mathrm{~s}$ and $\tau_{\Theta}^{\text {Frozen Front }}=4.37 \mathrm{~s}$, indicating that the thermal equilibrium between the shelf and the frozen layer is almost achieved in a several minutes, and between the frozen layer and the sublimation front in a few seconds. 
Interactive freeze-drying optimisation

\section{Heat transfer dynamics in the dry product layer}

A dynamic heat balance for the dry product layer was constructed in a similar way. The heat capacity of the dry layer includes that of the dry product and of the residual moisture and is much smaller than that of the frozen layer. In the lumped parameter formulation, the equivalent heat transfer coefficient between the sublimation front ant the dry layer is based on heat conduction through one half of the dry layer. The heat transfer between the dry layer and the chamber includes conduction through the other half of the dry layer and transfer between the product top and the chamber. With typical numerical values, the time constants are $\tau_{\Theta}^{\text {Front Dry }}=1.05 \mathrm{~s}$ and $\tau_{\Theta}^{\text {Dry Chamb }}=8.35 \mathrm{~s}$. Thermal equilibrium of the dry product layer is thus achieved in less than one minute.

\section{Mass transfer dynamics in the gaseous phase of the dry product layer}

A dynamic mass balance was established for the gaseous phase of the dry product layer. Vapour accumulation in the dry volume was expressed using the perfect gas law. With the lumped parameter formulation, the equivalent mass transfer coefficient between the dry layer and the sublimation front takes into account the transfer resistance of one half of the layer. The mass transfer coefficient between the dry layer and the chamber includes transfer resistance through the other half of the layer and between the product top and the chamber. In order to establish the time constants, the dynamic balance was rewritten in the following form:

$$
\frac{d P_{w}^{\text {Dry }}}{d t}=\frac{1}{\tau_{P}^{\text {Front Dry }}}\left(P_{w}^{\text {Front }}-P_{w}^{\text {Dry }}\right)-\frac{1}{\tau_{P}^{\text {DryChamb }}}\left(P_{w}^{\text {Dry }}-P_{w}^{\text {Chamb }}\right)
$$

With typical numerical values, one gets $\tau_{P}^{\text {Front Dry }}=3.9 \mathrm{~ms}$ and $\tau_{P}^{\text {Dry Chamb }}=7.2 \mathrm{~ms}$. The vapour pressure in the dry product layer reaches quasi steady state quite quickly (milliseconds), as physically expected. 


\section{APPENDIX 2. HEAT AND MASS TRANSFER MODEL EQUATIONS}

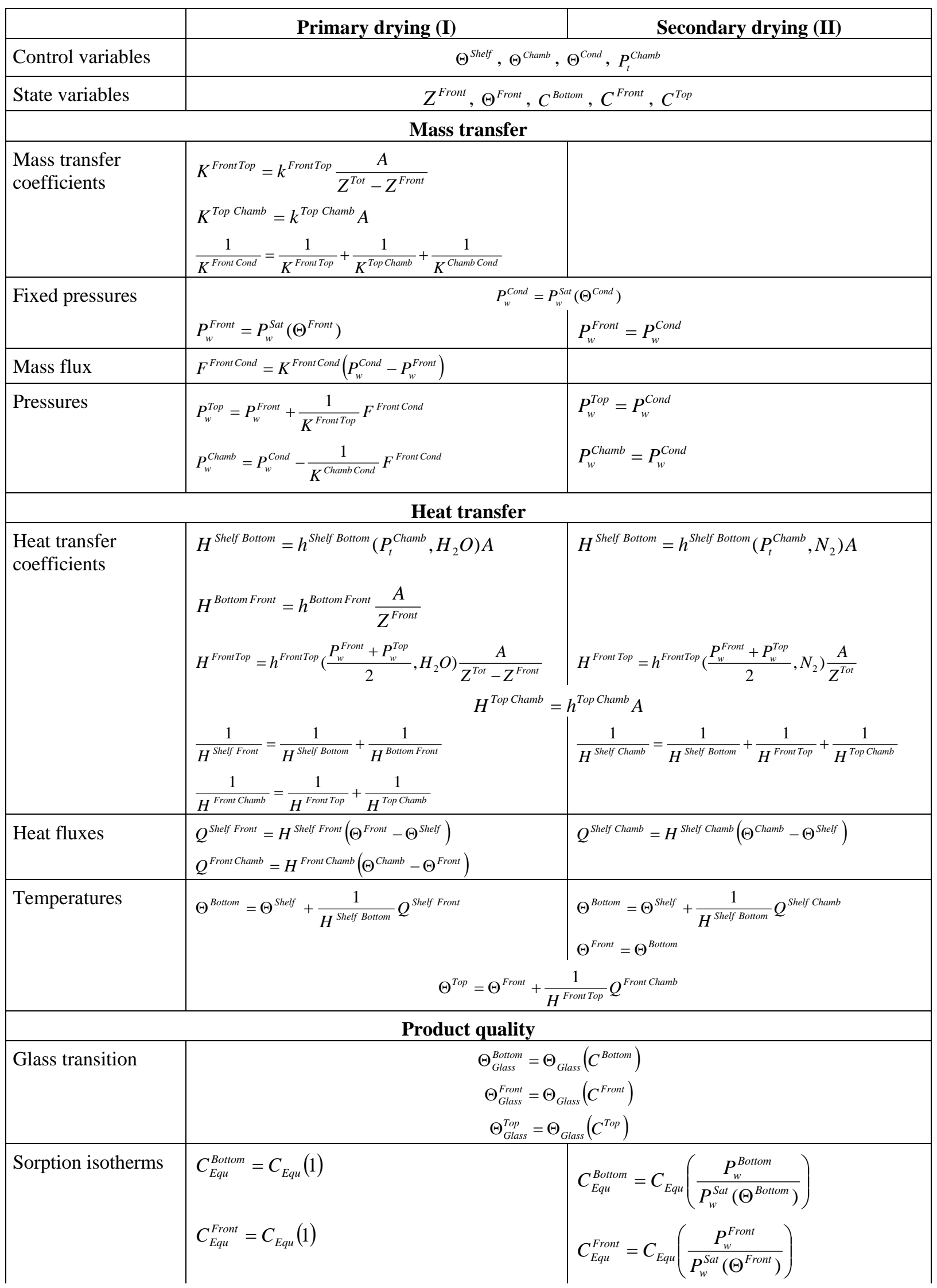




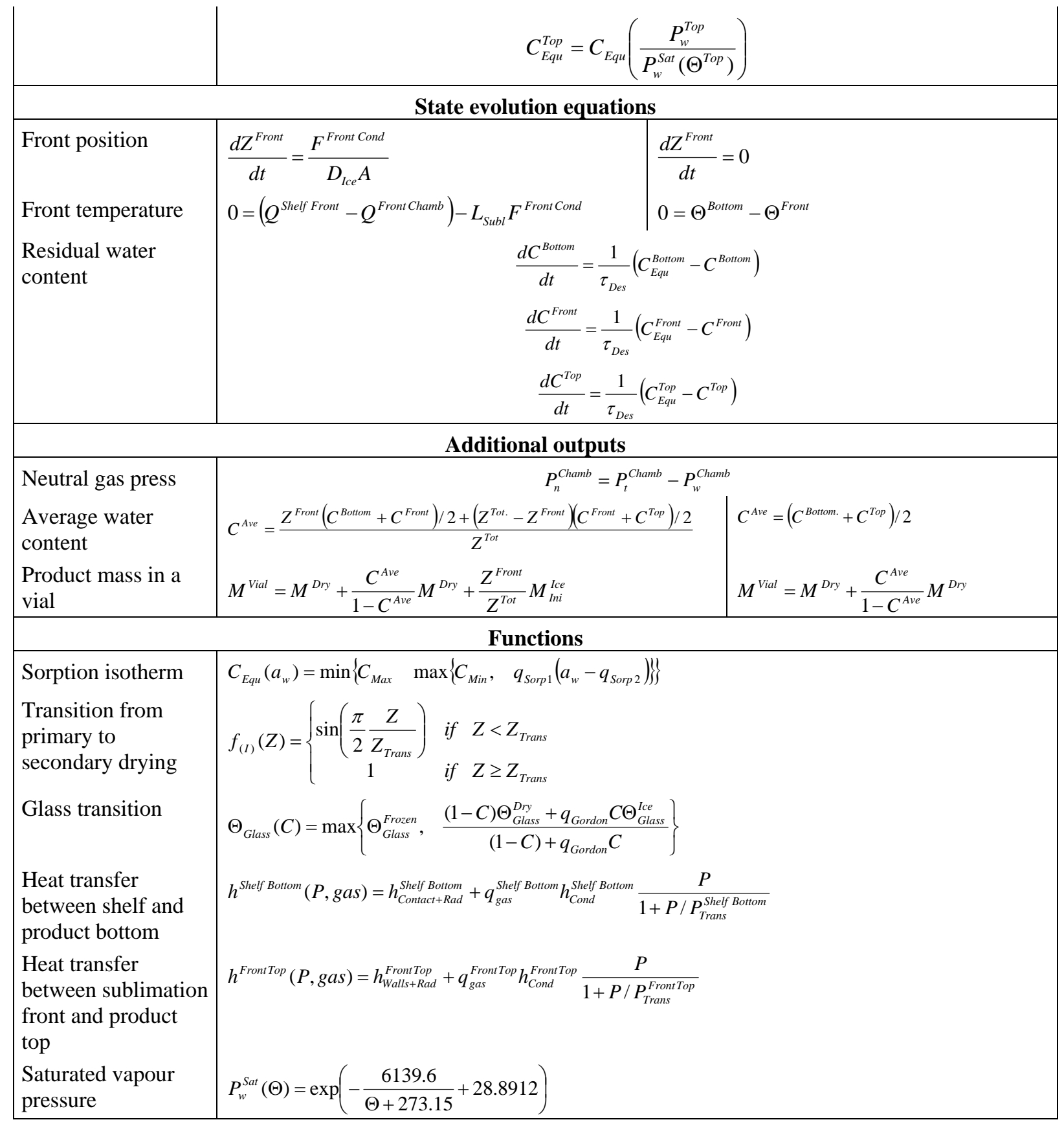

\section{REFERENCES}

1. Leuenberger, H., M. Plitzko and M. Puchkov. 2006. Spray freeze drying in a fluidized bed at normal and low pressure. Drying Technology 24: 711-719.

2. Pikal, M. J. 1985. Use of a laboratory data in freeze drying process design : heat and mass transfer coefficients and the computer simulation of freeze drying. Journal of Parenter Science and Technology 39: 115-138. 
Interactive freeze-drying optimisation

3. Chang, B. S. and N. L. Fisher. 1995. Development of an efficient single-step freeze-drying cycle for protein formulations. Pharmaceutical Research 12: 831-837.

4. Tang, X. L. and M. J. Pikal. 2004. Design of freeze-drying processes for pharmaceuticals: practical advice. Pharmaceutical Research 21: 191-200.

5. Pikal, M. J. and S. Shah. 1990. The collapse temperature in freeze-drying: dependence on measurement methodology and rate of water removal from the glassy state. International Journal of Pharmacy 62: 165-186.

6. Alves, O. and Y. H. Roos. 2006. Advances in multi-purpose drying operations with phase and state transitions. Drying Technology 24: 383-396.

7. Chouvenc, P., S. Vessot, J. Andrieu and P. Vacus. 2004. Optimization of the freeze-drying cycle: A new model for pressure rise analysis. Drying Technology 22: 1577-1601.

8. Sadikoglu, H. 2005. Optimal control of the secondary drying stage of freeze drying of solutions in vials using variational calculus. Drying Technology 23: 33-57.

9. Sadikoglu, H., M. Ozdemir and M. Seker. 2003. Optimal control of the primary drying stage of freeze drying of solutions in vials using variational calculus. Drying Technology 21: 1307-1331.

10. Nam, J. H. and C. S. Song. 2005. An efficient calculation of multidimensional freeze-drying problems using fixed grid method. Drying Technology 23: 2491-2511.

11. Hottot, A., R. Peczalski, S. Vessot and J. Andrieu. 2006. Freeze-drying of pharmaceutical proteins in vials: Modeling of freezing and sublimation steps. Drying Technology 24: 561-570.

12. Song, C. S., J. H. Nam, C. J. Kim and S. T. Ro. 2002. A finite volume analysis of vacuum freeze drying process of skim milk solution in trays and vials. Drying Technology 20: 283-305.

13. Mascarenhas, W. J., H. U. Akay and M. J. Pikal. 1997. A computational model for finite element analysis of the freeze-drying process. Computer Methods in Applied Mechanics and Engineering 148: 105-124.

14. Passot, S., F. Fonseca, M. Alarcon-Lorca, D. Rolland and M. Marin. 2005. Physical characterisation of formulations for the development of two stable freeze-dried proteins during both dried and liquid storage. European Journal of Pharmaceutics and Biopharmaceutics 60: 335-348. 
Interactive freeze-drying optimisation

15. Sadikoglu, H. and A. I. Liapis. 1997. Mathematical modelling of the primary and secondary drying stages of bulk solution freeze-drying in trays: parameter estimation and model discrimination by comparison of theoretical results with experimental data. Drying Technology 15: 791-810.

16. Nastaj, J. F. and B. Ambrozek. 2005. Modeling of vacuum desorption in freeze-drying process. Drying Technology 23: 1693-1709.

17. Gan, K. H., O. K. Crosser and A. I. Liapis. 2005. Lyophilization in vials on trays: Effects of tray side. Drying Technology 23: 341-363.

18. Hua, Z. Z., B. G. Li, Z. J. Liu and D. W. Sun. 2003. Freeze-drying of liposomes with cryoprotectants and its effect on retention rate of encapsulated ftorafur and vitamin A. Drying Technology 21: 1491-1505.

19. Gan, K. H., R. Bruttini, O. K. Crosser and A. I. Liapis. 2004. Heating policies during the primary and secondary drying stages of the lyophilization process in vials: effects of the arrangement of vials in clusters of square and hexagonal arrays on trays. Drying Technology 22: 1539-1575.

20. Adams, G. D. J. and J. R. Ramsay. 1996. Optimizing the lyophilization cycle and the consequences of collapse on the pharmaceutical acceptability of Erwinia L-Asparaginase. Journal of Pharmaceutical Sciences 85: 1301-1305.

21. Ronzi, E., A. Capalongo, G. Rovero, E. Bucci, S. Mondini and A. Falbo. 2003. Optimisation of a freezedrying process of high purity Factor VIII and Factor IX concentrates. Chemical Engineering and Processing 42: 751-757. 


\section{Nomenclature}

\begin{tabular}{lll} 
Symbol & Units & Significance \\
\hline $\mathrm{A}$ & $\mathrm{m}^{2}$ & Product cross area \\
$\mathrm{a}_{\mathrm{w}}$ & $\mathrm{Pa} / \mathrm{Pa}$ & Water activity \\
$\mathrm{C}$ & $\mathrm{kg} / \mathrm{kg}$ & Moisture content, wet basis \\
$\mathrm{D}$ & $\mathrm{kg} / \mathrm{m}^{3}$ & Density \\
$\mathrm{F}$ & $\mathrm{kg} / \mathrm{s}$ & Mass flux \\
$\mathrm{H}$ & $\mathrm{W} / \mathrm{K}$ & Heat transfer coefficient \\
$\mathrm{h}$ & $\mathrm{W} /(\mathrm{K} \mathrm{m})$ & Heat conductivity \\
$\mathrm{h}$ & $\mathrm{W} /\left(\mathrm{K} \mathrm{m}{ }^{2}\right)$ & Unitary heat transfer coefficient \\
$\mathrm{K}$ & $\mathrm{kg} /(\mathrm{s} \mathrm{Pa})$ & Mass transfer coefficient \\
$\mathrm{k}$ & $\mathrm{kg} /(\mathrm{s} \mathrm{Pa} \mathrm{m})$ & Mass conductivity \\
$\mathrm{k}$ & $\mathrm{kg} /\left(\mathrm{s} \mathrm{Pa} \mathrm{m}{ }^{2}\right)$ & Unitary mass transfer coefficient \\
$\mathrm{L}$ & $\mathrm{J} / \mathrm{kg}$ & Specific sublimation heat \\
$\mathrm{M}$ & $\mathrm{kg}$ & Mass for one vial \\
$\mathrm{N}$ & & Number \\
$\mathrm{P}$ & $\mathrm{Pa}$ & Pressure \\
$\mathrm{Q}$ & $\mathrm{W}$ & Heat flux \\
$\mathrm{q}$ & & Empirical model coefficient \\
$\mathrm{R}$ & $\mathrm{m}$ & Radius \\
$\mathrm{Z}$ & $\mathrm{m}$ & Position (height) in the product layer (origin = bottom) \\
$\Theta$ & $\mathrm{o} \mathrm{C}$ & Temperature \\
$\tau$ & $\mathrm{S}$ & Time constant \\
& & \\
\hline & &
\end{tabular}

\section{Upper indices}

\begin{tabular}{ll}
\hline Ave & Average \\
Bottom & Product bottom \\
Chamb & Chamber \\
Cond & Condenser \\
Dry & Dry product layer \\
Front & Sublimation front \\
Frozen & Frozen product layer \\
Ice & Ice \\
Sat & Saturation \\
Shelf & Temperature controlled shelf \\
Top & Product top \\
Tot & Total \\
Vial & Product vial
\end{tabular}


Interactive freeze-drying optimisation

\section{Lower indices}

(I)

(II)

Coll

Cond

Contact

Des

Equ

gas

Glass

Gordon

Ini

Max

Min

n

Rad

Sorp

$\mathrm{t}$

Trans

W

Walls
Primary drying stage

Secondary drying stage

Collapse

Conduction

By contact

Desorption

Equilibrium

Dominant gas composition: either water vapour $\left(\mathrm{H}_{2} \mathrm{O}\right)$ or nitrogen $\left(\mathrm{N}_{2}\right)$

Glass transition

Gordon-Taylor formula for glass transition temperature

Initial

Maximum

Minimum

Neutral gas (nitrogen)

By radiation

Sorption isotherm

Total

Transition; either from primary to secondary drying or from low pressure (molecular) to high pressure regime

Water vapour

Conduction through vial walls 
Interactive freeze-drying optimisation

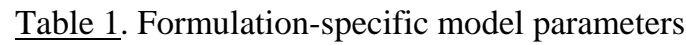

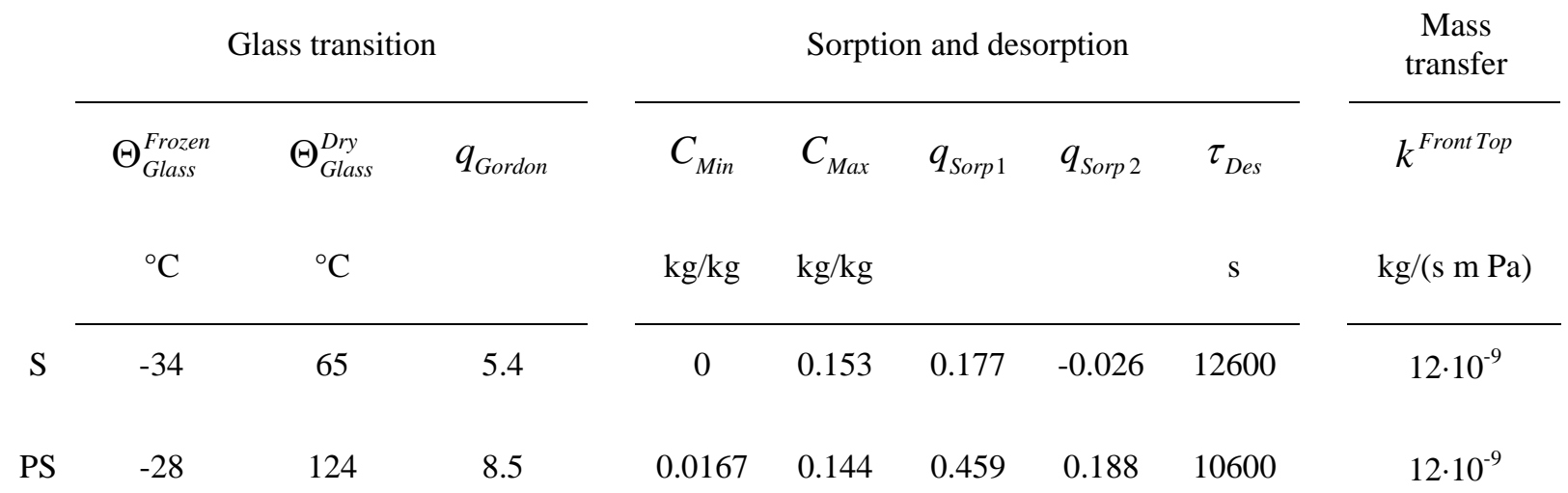

Table 2. Formulation-independent model parameters

Vials and filling

\begin{tabular}{cccccc}
\hline$N^{\text {Vial }}$ & $R^{\text {Vial }}$ & $M^{\text {Dry }}$ & $M_{\text {Ini }}^{\text {Ice }}$ & $Z^{\text {Tot }}$ & $Z^{\text {Trans }}$ \\
& & & & & \\
& $\mathrm{m}$ & $\mathrm{kg}$ & $\mathrm{kg}$ & $\mathrm{m}$ & $\mathrm{m}$ \\
\hline 213 & $7.12 \cdot 10^{-3}$ & $0.05 \cdot 10^{-3}$ & $0.95 \cdot 10^{-3}$ & $6.82 \cdot 10^{-3}$ & $1.70 \cdot 10^{-3}$
\end{tabular}

Ice properties

$\Theta_{\text {Glass }}^{\text {Ice }} \quad D^{\text {Ice }} \quad L_{\text {Subl }} \quad h^{\text {Bottom Front }}$

\begin{tabular}{cccc}
${ }^{\circ} \mathrm{C}$ & $\mathrm{kg} / \mathrm{m}^{3}$ & $\mathrm{~J} / \mathrm{kg}$ & $\mathrm{W} /(\mathrm{m} \mathrm{K})$ \\
\hline-135 & 920 & $2.83 \cdot 10^{6}$ & 2.4
\end{tabular}

Mass transfer

$k^{\text {Front Top }} \quad k^{\text {Top Chamb }} \quad K^{\text {Chamb Conc }}$

Heat transfer between shelf and product bottom

$\overline{h_{\text {Contact }+ \text { Rad }}^{\text {Shelf Bottom }}} q_{\mathrm{H}_{2} \mathrm{O}}^{\text {Shelf Bottom }} q_{N_{2}}^{\text {Shelf Bottom }} \quad h_{\text {Cond }}^{\text {Shelf Bottom }} P_{\text {Trans }}^{\text {Shelf Bottor }}$

$\mathrm{kg} /(\mathrm{s} \mathrm{m} \mathrm{Pa}) \quad \mathrm{kg} /\left(\mathrm{s} \mathrm{m}^{2} \mathrm{~Pa}\right) \quad \mathrm{kg} /(\mathrm{s} \mathrm{Pa})$

$$
\mathrm{W} /\left(\mathrm{m}^{2} \mathrm{~K}\right)
$$$$
\mathrm{W} /\left(\mathrm{m}^{2} \mathrm{~K} \mathrm{~Pa}\right)
$$

$\mathrm{Pa}$

$\begin{array}{lll}1.2 \cdot 10^{-8} & 8 \cdot 10^{-6} & 5 \cdot 10^{-7}\end{array}$

1
1

0.625

0.6

100

Heat transfer between sublimation front and product top

\begin{tabular}{ccccc}
\hline$h_{\text {Walls }+ \text { Rad }}^{\text {Front Top }}$ & $q_{\mathrm{H}_{2} \mathrm{O}}^{\text {Front Top }}$ & $q_{N_{2}}^{\text {Front Top }}$ & $h_{\text {Cond }}^{\text {Front Top }}$ & $P_{\text {Trans }}^{\text {Front Top }}$ \\
$\mathrm{W} /(\mathrm{m} \mathrm{K})$ & & & $\mathrm{W} /(\mathrm{m} \mathrm{K} \mathrm{Pa})$ & $\mathrm{Pa}$ \\
\hline $50 \cdot 10^{-3}$ & 1 & 0.813 & $327 \cdot 10^{-6}$ & 100
\end{tabular}


Interactive freeze-drying optimisation

Table 3. Optimisation results for the shelf temperature profile

\begin{tabular}{cccc} 
Formulation & $\begin{array}{c}\text { Initial (maximum) shelf } \\
\text { temperature in primary } \\
\text { drying } \\
{ }^{\circ} \mathrm{C}\end{array}$ & $\begin{array}{c}\text { Final (minimum) shelf } \\
\text { temperature in primary } \\
\text { drying } \\
{ }^{\circ} \mathrm{C}\end{array}$ & Total cycle duration \\
\hline S & -29 & -48 & 36 \\
PS & +12 & -30 & 24
\end{tabular}




\section{Heat transfer}

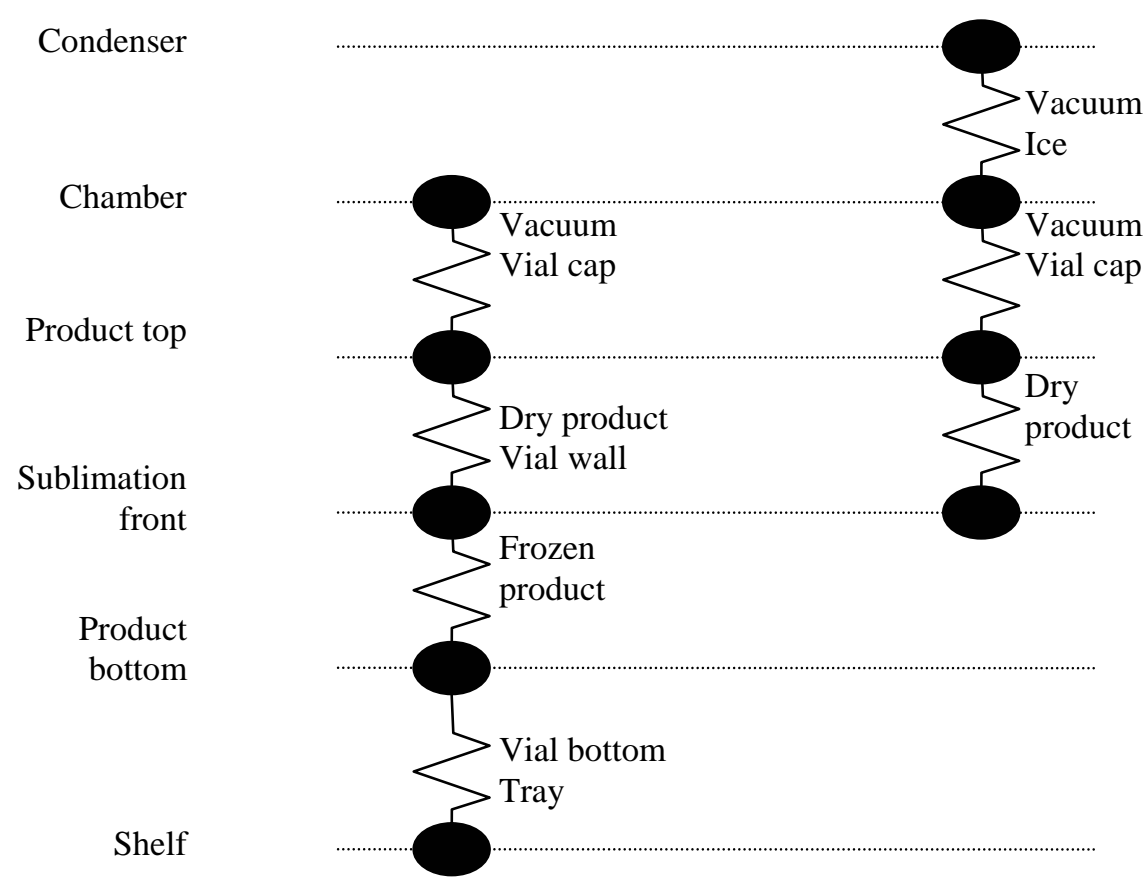

Figure 1. Schematic representation of heat and mass transfers between the characteristic points in the product and in the freeze-dryer. 

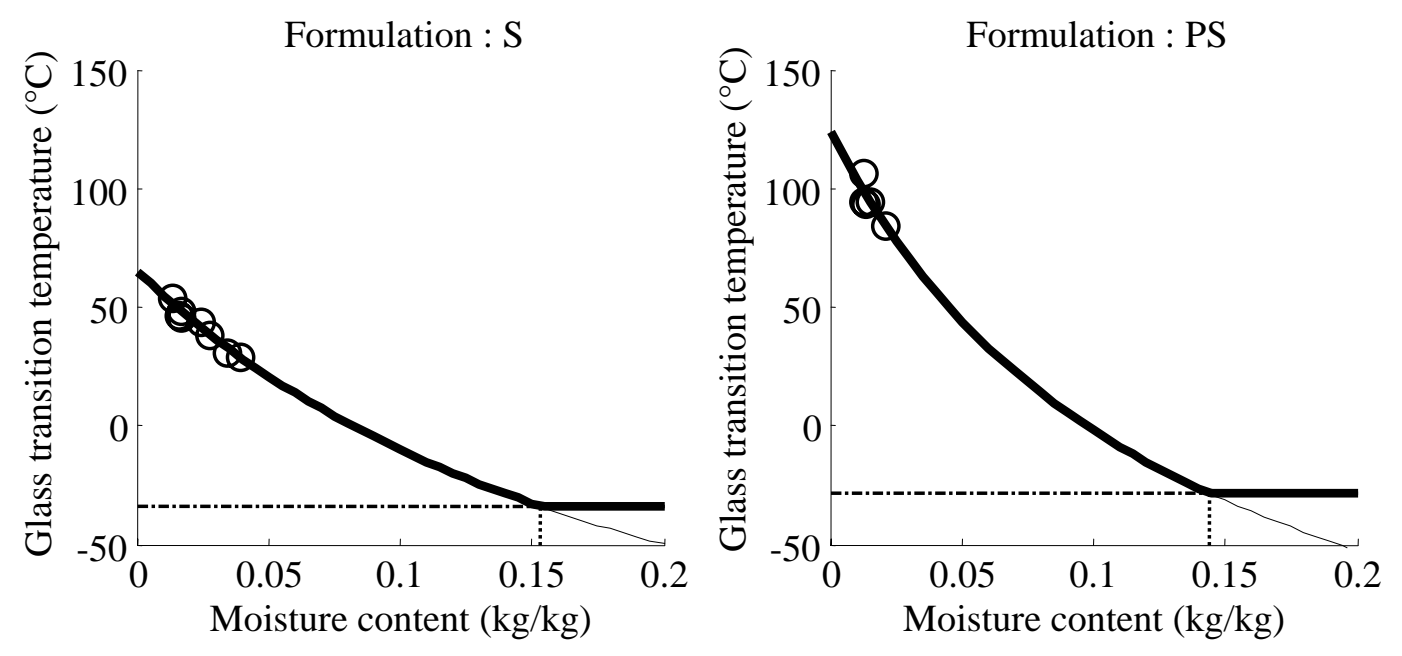

Figure 2. Glass transition temperature models. Measured values in dry product (o), measured value in frozen product $(-\cdot-)$, Gordon-Taylor model (-), maximum moisture content of the freeze-concentrated product (…). 
Interactive freeze-drying optimisation

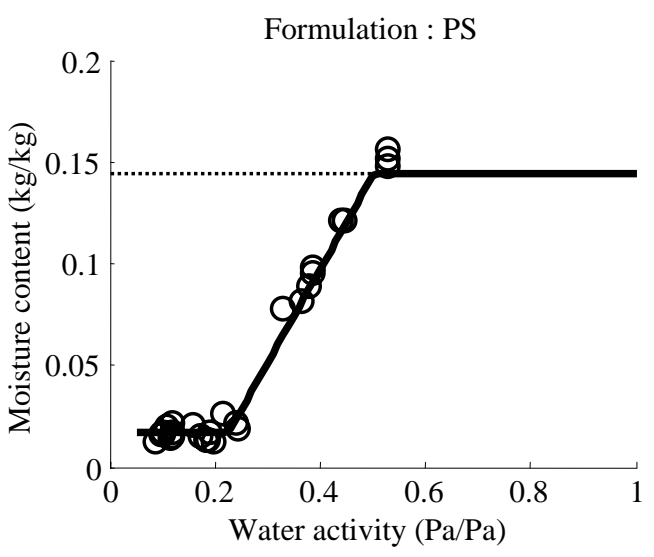

Figure 3. Sorption isotherm models. Measured values (o), piecewise linear model (-), maximum moisture content of the freeze-concentrated product (….). 

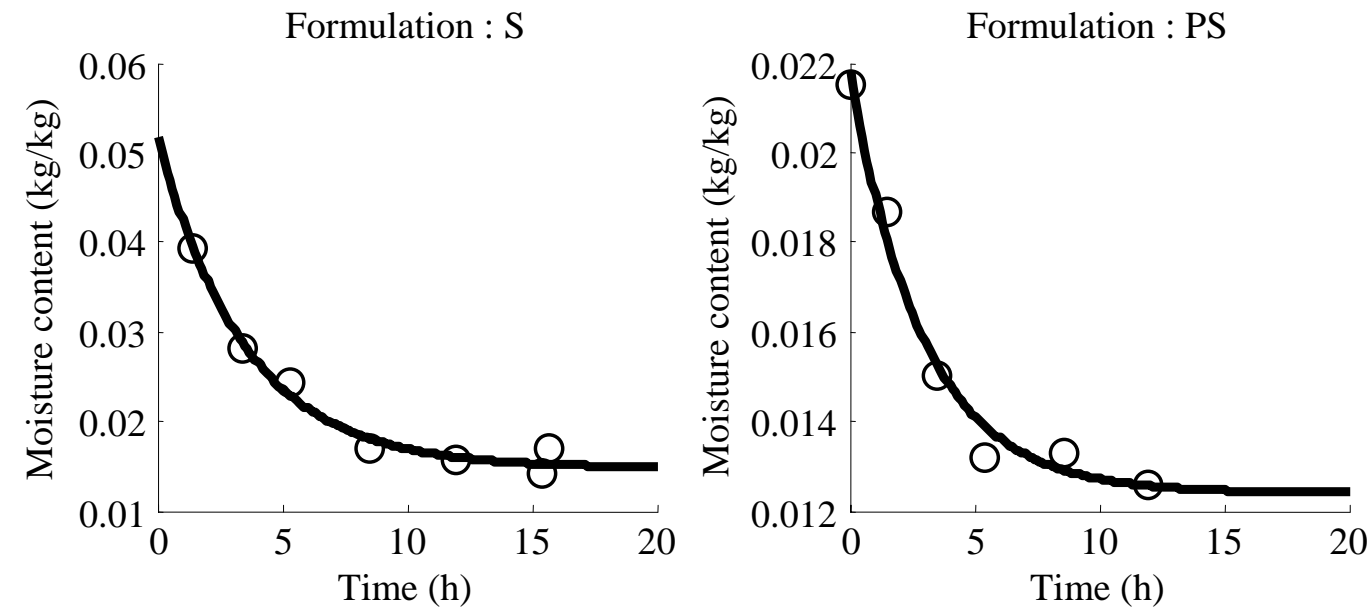

Figure 4. Desorption kinetics. Measured values (o), exponential first order rate model (-). 

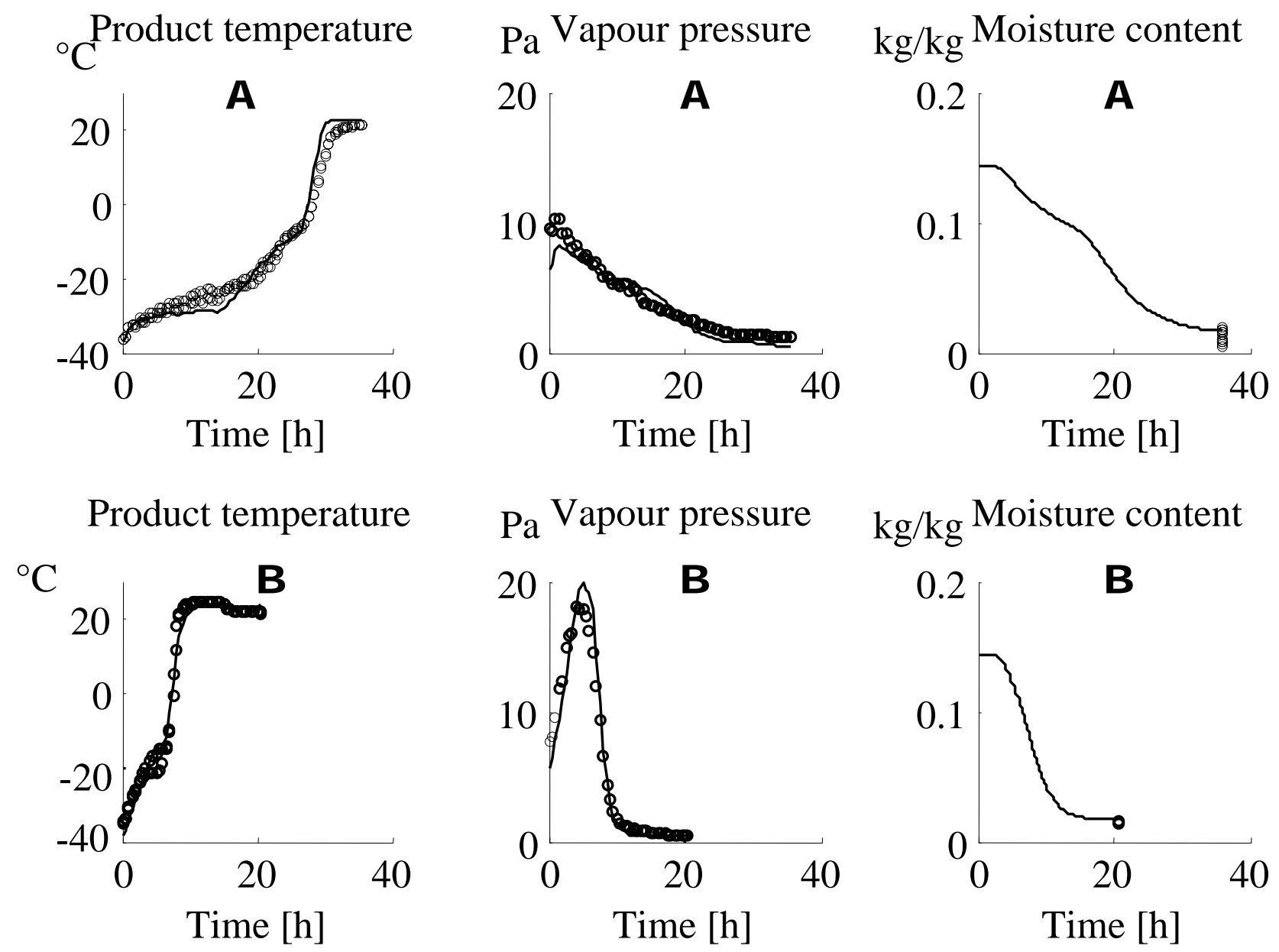

$\mathrm{kg} / \mathrm{kg}$ Moisture content

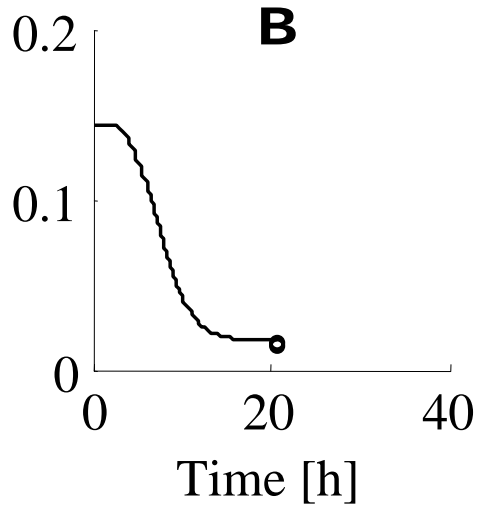

Figure 5. Dynamic model validation. Formulation: PS. A: Shelf temperature at $-25^{\circ} \mathrm{C}$ and total chamber pressure at $10 \mathrm{~Pa}$ during primary drying. B: Shelf temperature at $+25^{\circ} \mathrm{C}$ and total chamber pressure at $34 \mathrm{~Pa}$ during primary drying. Measured values (o) and model predictions (-). 


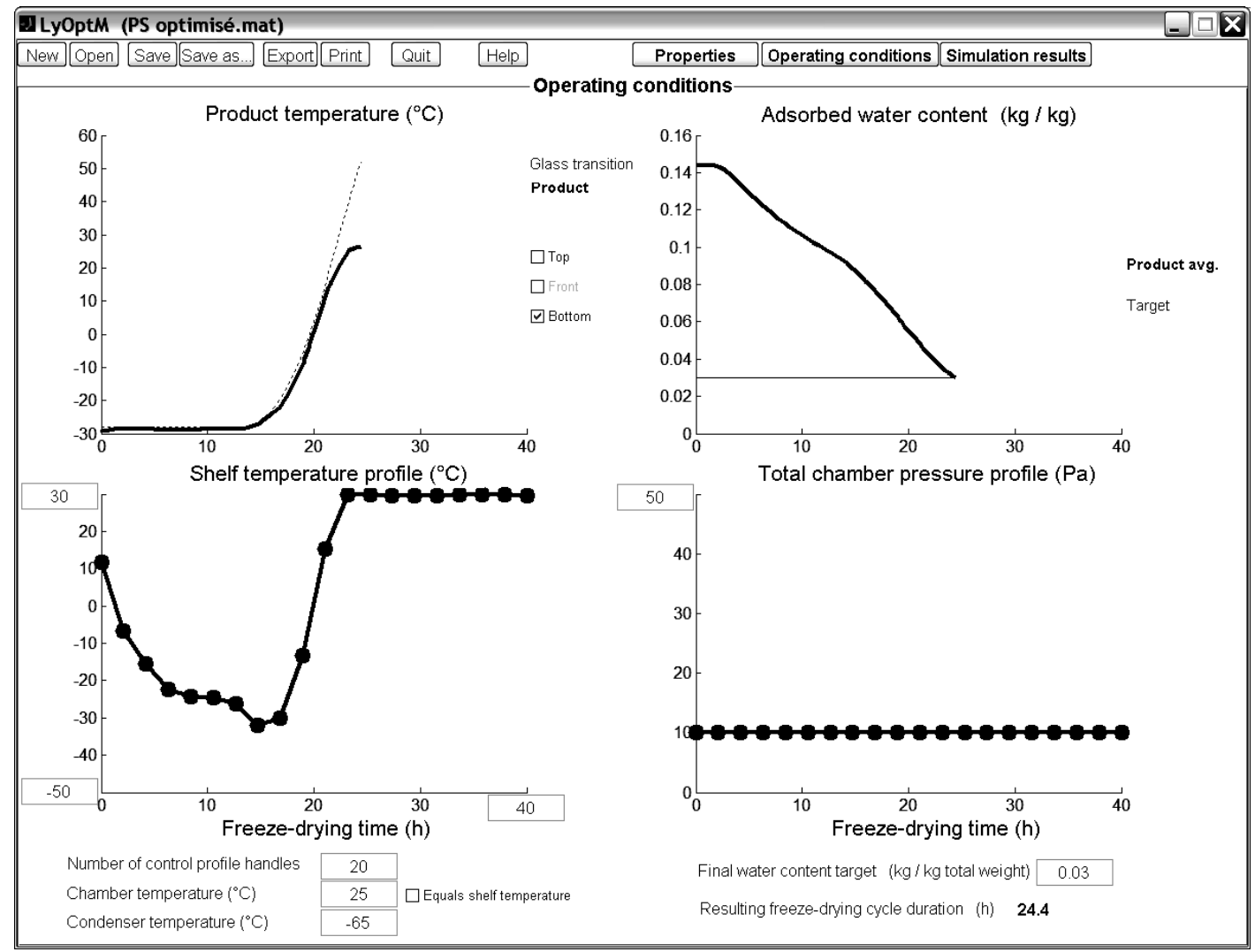

Figure 6. Screenshot of the freeze-drying cycle optimisation tool. Interactive selection of the operating conditions for the PS formulation. 